\title{
Experimentos reais e virtuais: proposta para o ensino de eletricidade no nível médio
}

\author{
Virtual and real experiments: a proposal to teach electricity in High School \\ José Carlos dos Santos ${ }^{1}$, Adriana Gomes Dickman*2] \\ ${ }^{1}$ Centro Estadual de Educação Tecnológica "Paula Souza", Escola Técnica Estadual Prof. José Sant’Ana de Castro, Cruzeiro, \\ SP, Brasil \\ ${ }^{2}$ Pontifícia Universidade Católica de Minas Gerais, Programa de Pós-graduação em Ensino de Ciências e Matemática, Belo \\ Horizonte, MG, Brasil
}

Recebido em 31 de Maio, 2018. Revisado em 25 de Junho, 2018. Aceito em 02 de Julho, 2018.

\begin{abstract}
Neste trabalho é relatado o processo de elaboração e aplicação de um roteiro de atividades para professores do Ensino médio consistindo de estratégias para o ensino de tópicos de eletricidade utilizando laboratórios reais e virtuais. Quatro estratégias diferentes foram testadas com alunos do terceiro ano do ensino médio com o objetivo de identificar qual seria mais efetiva para ensinar circuitos elétricos e a Lei de Ohm. Cada estratégia foi caracterizada por uma sequência específica de abordagem, tais como aulas expositivas, simulações computacionais ou atividades experimentais, para discutir o tópico. Os resultados indicam que a abordagem experimental, seja virtual ou real, apresenta uma vantagem significativa sobre as aulas teóricas, reforçando a importância da utilização de atividades experimentais na sala de aula.
\end{abstract}

Palavras-chave: Ensino de física. Simulações computacionais. Atividades experimentais. Eletricidade.

We report on the elaboration and application of a guide of activities for High School teachers consisting of strategies to teach topics in electricity using real and virtual laboratories. We tested four different strategies with students in the final year of high school to figure out which would be more effective to teach about electric circuits and Ohm's law. Each strategy was characterized by a specific sequence of approaches, such as lectures, computer simulations or experiments, to present the subject. Our results indicate that the experimental approach, virtual or real, has a significant advantage over lectures, reinforcing the importance of using experimental activities in the classroom.

Keywords: Physics education. Computer simulations. Real experiments. Electricity.

\section{Introdução}

O ensino de Física na Educação Básica, via de regra, se resume à apresentação de conteúdos pelo professor e resolução de exercícios, em geral, sem a realização de práticas em laboratório ou o uso de tecnologias ( $\mathrm{TIC}^{1}$ ) no ensino. Esses fatores contribuem para deixar a Física desestimulante e sem sentido para os estudantes, amargando altos índices de reprovação, tanto no ensino médio como no ensino superior.

Segundo os Parâmetros Curriculares Nacionais (PCN+), a Física deve ser apresentada para o aluno do ensino médio "como um conjunto de competências específicas que permitam perceber e lidar com os fenômenos naturais

*Endereço de correspondência: adrianadickman@gmail.com

1 O significado da abreviatura é Tecnologias de Informação e Comunicação. Neste trabalho será utilizada a palavra tecnologias quando se referir às TICs. De acordo com Fiorentini e Lorenzato (2012, p. 45) [1], "as TICs resultam da fusão das tecnologias de informação, antes referenciadas como informática, e as tecnologias de comunicação, denominadas anteriormente como telecomunicações e mídia eletrônica". e tecnológicos, presentes tanto no cotidiano mais imediato quanto na compreensão do universo distante [...]" [2]. Neste contexto, uma proposta de ensino que incentive a utilização de atividades experimentais está em pleno acordo com esta orientação. Entretanto, a implementação dessa proposta faz surgir a seguinte questão: Atividades experimentais, realizadas em laboratório com equipamentos reais ou virtualmente, feitas através de simulações computacionais, trazem, de fato, vantagens ao aprendizado dos alunos, quando comparadas com as aulas expositivas tradicionais? Se a resposta a esta questão for afirmativa, há o interesse em verificar se uma dessas abordagens, real ou virtual, tem preponderância sobre a outra no que diz respeito ao aprendizado.

Desta forma, neste trabalho é feito um estudo comparativo destes recursos, com o objetivo de se investigar se estes contribuem para o aprendizado dos alunos e se há vantagem de um sobre o outro. Para tal, toma-se como base um experimento para a verificação da Lei de Ohm, assunto que faz parte da programação de Física 
do terceiro ano do ensino médio da maioria das escolas brasileiras.

A proposta aqui apresentada consiste em alternar abordagens experimentais reais e virtuais, além de teóricas, a fim de comparar os dados entre as turmas, verificando o efeito na aprendizagem dos alunos. Assim, foram elaboradas quatro estratégias com o intuito de investigar qual delas seria mais efetiva para a assimilação de conteúdo, motivação e interesse dos estudantes, bem como para a contextualização do conteúdo. Entende-se que há a possibilidade de se constatar que não há diferenças significativas entre estas estratégias. Este resultado também seria interessante, pois o professor poderia escolher livremente qualquer abordagem de acordo com a sua realidade, disponibilidade de materiais, ou mesmo particularidade da turma.

\section{Uso de experimentos no ensino de física}

Não é de hoje que os alunos do ensino médio apresentam uma grande dificuldade no aprendizado da Física. Muitos alunos desenvolvem uma verdadeira repulsa ao componente curricular, o que prejudica consideravelmente o trabalho em sala de aula. Segundo Fiolhais e Trindade (2003, p. 259) [3] "entre as razões do insucesso na aprendizagem em Física são apontados métodos de ensino desajustados das teorias de aprendizagem mais recentes, assim como a falta de meios pedagógicos modernos". De acordo com Alves (2006, p. 11) [4], "as questões relativas ao processo ensino-aprendizagem em Física, principalmente em nível médio, têm sido tema de várias pesquisas nessas últimas décadas, as quais têm identificado várias causas para tal situação". O autor ainda destaca "a quase inexistência de equipamentos e atividades práticas/experimentais e as dificuldades metodológicas e didáticas dos professores". Sá (2003, p. 23) [5] acrescenta que

No Brasil, a atividade experimental não faz parte da rotina de todos os cursos de Ciências. Tanto no Ensino Fundamental como no Ensino Médio, os cursos estão estruturados a enfatizar a solução algorítmica de problemas padronizados do tipo "lápis e papel" e a memorização de regras, fatos e princípios.

Este fato vai contra a orientação dos $\mathrm{PCN}+[2]$, segundo os quais o ensino de física deve deixar de concentrarse na simples memorização de fórmulas ou repetição automatizada de procedimentos, em situações artificiais ou excessivamente abstratas, consequentemente contribuindo para deixar as aulas desinteressantes para o aluno, resultando em baixo aproveitamento. Segundo Ribeiro, Almeida e Carvalho (2012, p.2) [6],

Cada vez mais torna-se necessário para o professor estabelecer estratégias que procurem tornar o ensino da física mais completo e, complementarmente, mais atrativo. Daí a necessidade das atividades laboratoriais no contexto do ensino da física.

Seré, Coelho e Nunes (2003, p. 39) [7] destacam que,

Graças às atividades experimentais, o aluno é incitado a não permanecer no mundo dos conceitos e no mundo das "linguagens", tendo a oportunidade de relacionar esses dois mundos com o mundo empírico. Compreende-se, então, como as atividades experimentais são enriquecedoras para o aluno, uma vez que elas dão um verdadeiro sentido ao mundo abstrato e formal das linguagens.

Ribeiro, Almeida e Carvalho (2012, p.4317-1) [6] afirmam ainda que "a atividade experimental permite ao aluno associar a razão à observação e pode funcionar tanto como motivação do que se vai estudar, como verificação do que foi estudado".

A atividade experimental em sala de aula, mesmo que seja uma demonstração experimental feita pelo professor, é de grande importância. De acordo com Monteiro et al (2010, p.371) [8], "a demonstração experimental é uma atividade que tem sido pouco explorada em sala de aula, em parte, pelas dificuldades enfrentadas pelo professor em ter à sua disposição os equipamentos de demonstração". De acordo com a experiência de um dos autores deste trabalho em escolas de ensino médio e técnico, podese afirmar que a experimentação, seja no formato de uma demonstração feita pelo professor ou uma atividade prática completa, deixa a aula mais interessante, fato confirmado por Alves (2006, p. 129-130) [4]:

Podemos, portanto, afirmar que o melhor desempenho dos alunos do grupo experimental foi, de fato, devido ao tratamento ao qual foram submetidos, no qual as atividades experimentais, com todo o seu potencial e planejadas de acordo, têm um papel fundamental.

Apesar de todas as dificuldades e obstáculos, percebese a importância de incorporar atividades experimentais no ensino de física, propiciando além da motivação, momentos de discussão e reflexão, o que contribui para facilitar o aprendizado.

\subsection{Atividades experimentais com simulações computacionais}

Sabe-se que boa parte das escolas de ensino fundamental e médio brasileiras não dispõe de um laboratório didático de Ciências (Física, Química e Biologia), mas não é raro encontrar escolas com laboratórios de informática. Aliado ao fato de que muitos experimentos de Física podem ser feitos com o auxílio de simulações computacionais, o que pode ser uma alternativa à falta de laboratórios de ciências, ou até mesmo um complemento para a prática 
de atividades experimentais - pode ser viável para o professor reservar algumas aulas para experimentos fáceis de montar, utilizando materiais de baixo custo e fácil obtenção, e em outras aulas experimentos executados a partir de softwares, que simulam atividades reais. Além disso, afirma Cenne (2007, p. 13) [9], que

os PCNEM indicam a necessidade das tecnologias serem incorporadas no aprendizado escolar como instrumento para a cidadania, para as relações sociais e para o trabalho, explicitando que o domínio dos recursos didáticos, como as novas tecnologias, também deve ser um objetivo do ensino da área de Ciências Naturais e Matemática.

Segundo Rosa (1995, p. 183) [10], "as potencialidades do uso de computadores no ensino de Física são grandes", destacando: "a coleta e análise de dados em tempo real, a simulação de fenômenos físicos, a instrução assistida por computador, a administração escolar e o estudo de processos cognitivos".

Neste trabalho dá-se ênfase à investigação do uso do computador na simulação de fenômenos físicos pelos alunos. Há consideráveis vantagens em se trabalhar realidade virtual com os alunos do ensino médio. Fiolhais e Trindade (2003, p. 268) [3] comentam que,

As principais características que a realidade virtual disponibiliza em benefício da educação são a imersão (a maioria das sensações provém do ambiente virtual), interatividade (navegação livre, escolha do referencial, etc) e a manipulação (ações realizadas pelo utilizador tal como no mundo real).

Essas características fascinam o jovem estudante, aguçando seu interesse e curiosidade, abrindo ainda a possibilidade de o mesmo trabalhar com simulações computacionais em casa e trazer novos fatos à sala de aula.

Um projeto interessante e viável nessa linha é o PhET Interactive Simulations ${ }^{2}$ Trata-se de um projeto desenvolvido pela Universidade do Colorado, que disponibiliza diversas simulações, gratuitas, de fácil instalação e utilização, permitindo ainda a colaboração de professores na proposta de atividades. Em várias simulações, o PhET permite ao aluno montar o experimento, variando alguns parâmetros, como se estivesse em um laboratório real.

\footnotetext{
${ }^{2}$ As simulações, disponíveis em https://phet.colorado.edu/pt_BR/, estão divididas nas áreas das ciências - Física, Química e Biologia - e são apresentadas em vários idiomas, inclusive em Português, o que é um facilitador para a utilização por professores e alunos. Há atividades bem simples e outras mais elaboradas, que permitem ao aluno explorá-las, utilizando os conceitos de Física que têm influência sobre os resultados, contribuindo assim para a sua aprendizagem efetiva. O professor pode optar em utilizar o programa online, como também pode instalar o programa em suas máquinas, fazendo o uso off-line.
}

Essas possibilidades podem e devem ser trabalhadas com os alunos.

Segundo Fiolhais e Trindade (2003, p. 264) [3], "embora as simulações não devam substituir por completo a realidade que representam, elas são bastante úteis para abordar experiências difíceis ou impossíveis de realizar na prática". Medeiros e Medeiros (2002, p. 3) [11] reforçam esta constatação: "as simulações podem ser bastante úteis, principalmente quando a experiência original for impossível de ser reproduzida pelos estudantes".

Nesta linha de trabalho, Macêdo, Dickman e Andrade (2012) [12] aplicaram um roteiro de atividades sobre materiais condutores e isolantes, baseado em simulações computacionais do PhET, a uma turma do terceiro ano do Ensino médio. A avaliação de dados, coletados por questionários pré- e pós-teste, mostrou que as atividades promoveram uma mudança conceitual nos alunos, permitindo a assimilação do tópico discutido.

Finkelstein et al (2005) [13] investigaram os efeitos de substituir equipamentos reais por simulações computacionais (PhET) em um laboratório de eletricidade. O estudo envolveu grupos de controle no estudo de circuitos de corrente contínua simples, em que uma turma trabalhou apenas com simulações, enquanto outra trabalhou apenas com equipamentos reais, e ainda uma terceira turma, que não participou de aulas práticas. A análise dos resultados dos exames finais destes alunos mostrou que o grupo que trabalhou com equipamentos simulados teve um rendimento melhor, indicando uma melhor compreensão conceitual do tópico abordado. Dados observacionais mostraram que estes alunos apresentaram melhor coordenação durante a tarefa de montar circuitos reais e descrever seu funcionamento.

Comparações entre atividades envolvendo experimentos reais e virtuais, ou uma combinação de ambos, são temas de vários trabalhos em que o público-alvo é formado por alunos da graduação ou professores de física, explorando tópicos como calor e temperatura $[14,15]$, eletromagnetismo [16, 17], mecânica, óptica e física térmica [18], e circuitos elétricos [19]. Os resultados indicam que a experimentação, seja ela real ou virtual, é bastante efetiva no aumento da compreensão conceitual dos alunos. Zacharia e Anderson [18] utilizaram simulações antes da condução de experimentos no laboratório. Foi observado que o contato com as simulações melhorou a habilidade dos alunos em fazer previsões aceitáveis dos fenômenos quando deparados com experimentos reais. Nos trabalhos [15, 19], notou-se melhor compreensão conceitual dos estudantes na combinação de experimentos reais com virtuais, quando comparado com a manipulação de experimentos reais apenas. Estes trabalhos mostram que independente da ordem de aplicação de experimentos reais ou virtuais sempre há ganhos conceituais.

Outros três trabalhos investigaram a combinação de atividades experimentais reais e virtuais, em alunos do Ensino fundamental [20] e do Ensino médio [21, 22]. Jaakkola e Nurmi (2008) [20] perceberam que a integração 
de atividades no estudo de circuitos elétricos levou a um ganho de aprendizagem maior do que quando os alunos trabalharam apenas com atividades reais ou virtuais, separadamente. Não foram observadas diferenças conceituais nos alunos quando estes tiveram contato com apenas uma das atividades. Ronen e Eliahu (2000) [21] distribuíram tarefas experimentais sobre circuitos elétricos, disponibilizando um ambiente de simulação apenas para um dos grupos. Houve diferenças significativas, mostrando que o uso de simulação contribuiu para aumentar a confiança e motivação, evitando que os alunos desistissem da tarefa. Moro, Neide e Rehfeldt (2016) [22] investigaram a integração de atividades experimentais e virtuais no estudo de física térmica, percebendo-se uma grande motivação dos alunos, além de uma contribuição para uma aprendizagem significativa.

A proposta aqui apresentada é bastante próxima do estudo realizado nos trabalhos de Finkelstein et al (2005) [13] e Ronen e Eliahu (2000) [21] com o objetivo de comparar o uso de equipamentos virtuais e reais em sala de aula para ensinar tópicos de circuitos elétricos para alunos do Ensino médio. Entretanto, a presente investigação abrange também o estudo da melhor combinação de abordagens envolvendo aulas teóricas expositivas, permeadas pela manipulação de equipamentos reais e virtuais. Vale ressaltar que nenhum dos trabalhos citados explorou a Lei de Ohm e dispositivos não-ôhmicos, tema desta pesquisa. Apenas Finkelstein et al (2005) [13] utilizou a simulação disponibilizada pelo projeto $P h E T$.

\section{Metodologia}

Neste trabalho foram elaborados roteiros de estudo com atividades experimentais reais e virtuais, acompanhadas ou não por aulas expositivas, sobre Circuitos elétricos e Lei de Ohm. O objetivo desta investigação foi verificar se atividades experimentais têm melhor efeito sobre a aprendizagem dos alunos, quando comparadas ou combinadas com aulas expositivas tradicionais. Também foi verificada se haveria alguma diferença significativa, no quesito aprendizagem, quando se utiliza atividade experimental com equipamentos reais ou com simulações computacionais.

Optou-se por concentrar este estudo em um assunto que faz parte do Eletromagnetismo, por ser esse um ramo da física abstrato e no qual estudantes apresentam grande dificuldade de aprendizado. De acordo com Monteiro et al (2010, p. 372) [8],

atividades didáticas que possibilitem contextualizações de fenômenos eletromagnéticos, permitindo ao professor meios de demonstrar efeitos que justifiquem modelos conceituais e matemáticos relativos às ideias de campo elétrico, campo magnético, fluxo, corrente elétrica, vetores, entre outros, são fundamentais para a superação das dificuldades comumente encontradas no ensino desses conceitos científicos.

Segundo a classificação de Scarpa e Marandino (1999) [23], a pesquisa se enquadra na categoria de Testagem de Métodos, Materiais ou Programas, uma vez que o trabalho realiza um teste sobre a eficácia da utilização de recursos didáticos no ensino, com uso de elementos de pesquisas empíricas. Segundo Fiorentini e Lorenzato (2012, p. 63-64) [1], deve-se observar que "a técnica de ensino seria uma variável independente e o desempenho dos alunos a variável dependente, pois se tem como hipótese que, variando a técnica de ensino, o desempenho (rendimento) dos alunos também varie".

\subsection{Estratégias de ensino e sua aplicação}

As estratégias foram aplicadas em quatro turmas de terceiro ano (Turmas $3^{\circ} \mathrm{A} ; 3^{\circ} \mathrm{B} ; 3^{\circ} \mathrm{C}$ e $3^{\circ} \mathrm{D}$ ) de uma escola estadual de São Paulo que oferece ensino médio e cursos técnicos. Apresentam-se nesta subseção as características e o processo de aplicação das quatro estratégias elaboradas para testar nossa hipótese. Em Santos (2015), [24] estão reunidos quadros mostrando em detalhes o passo-a-passo de cada uma delas.

Optou-se pelo tema circuitos elétricos e Lei de Ohm, tópicos que fazem parte da programação de Física, no terceiro ano do Ensino Médio. Além disso, a apresentação desses assuntos coincidiu com a programação da unidade escolar de um dos autores deste trabalho, permitindo a aplicação das atividades durante as aulas de Física, sem necessitar que os alunos viessem fora do seu horário normal de aulas. Este fato permite trabalhar mais próximo da situação real - todos os alunos de cada turma participaram da pesquisa, ou seja, o universo da pesquisa abrangeu alunos com interesses diversificados em relação ao componente curricular.

Em seguida foi elaborada uma avaliação, aplicada como pré e pós-teste, na qual fosse possível identificar se os alunos tinham algum conhecimento prévio sobre o assunto, e como foi o progresso desses alunos após as aulas, após a participação em cada abordagem.

Nas estratégias, os alunos foram informados de que toda orientação referente à atividade experimental estaria no roteiro distribuído no início da aula. Após a conclusão das atividades, sejam elas a execução das medidas em laboratório ou atividades virtuais, o que durava em torno de duas aulas (100 minutos), incluído o tempo para a orientação inicial do professor, os alunos foram encaminhados para a biblioteca, a fim de confeccionarem um relatório (o que durava, geralmente mais 100 minutos, apesar de alguns grupos terem demorado um pouco mais). Os relatórios foram avaliados pelo professor, que os devolveu aos alunos. Por fim, foram aplicadas as avaliações (uma dissertativa, que foi a mesma aplicada no pré-teste com algumas modificações) e outra de múltipla escolha inédita. 
Os resultados do pré-teste aplicado aos alunos deram base para a escolha da abordagem para cada turma, tendo sido considerada a média do aproveitamento da turma. Uma vez divididas as turmas, foram verificados os equipamentos e dispositivos disponíveis no laboratório e os que deveriam ser adquiridos. Os experimentos foram testados, para identificar possíveis falhas que pudessem ocorrer. Nesta etapa, já se pode perceber algumas vantagens e desvantagens de se usar uma ou outra abordagem, que são comentadas na discussão dos resultados.

\section{E1: Abordagem teórica seguida da abordagem experimental real}

A Estratégia 1 (E1) iniciou-se com uma abordagem teórica, apoiada na aula tradicional - aula expositiva dialogada, com resolução de exercícios em sala de aula. Após a abordagem teórica, foi aplicada uma avaliação para se averiguar o nível de aprendizado dos alunos. Em seguida, aplicaram-se duas atividades experimentais com equipamentos reais, trabalhando-se com resistores e lâmpada incandescente. Nesta abordagem, para as atividades experimentais a sala foi dividida em turmas de 20 alunos. Os alunos foram orientados a trabalhar em trios, o que permitiu que todos trabalhassem durante a aula.

Em um primeiro momento, com acompanhamento do professor, foi solicitado aos alunos que montassem um circuito elétrico simples com uma lâmpada, como mostrado na figura 1(a), a fim de verificarem seu funcionamento. Os alunos foram orientados a montar outro circuito, substituindo a lâmpada pelo resistor, e depois inserindo o amperímetro, como mostra a figura 1(b). Em seguida, os alunos ligaram o voltímetro nos polos do resistor, e fizeram a anotação das medidas. Caso os alunos se confundissem na montagem do circuito, durante a colocação dos instrumentos de medida, foi-lhes solicitado que desmontassem todo o circuito e iniciassem novamente a montagem pelo circuito simples.

Em outra data, os alunos fizeram outra atividade experimental, semelhante a esta, mas utilizando somente a lâmpada, com a coleta de dados (corrente e tensão), com

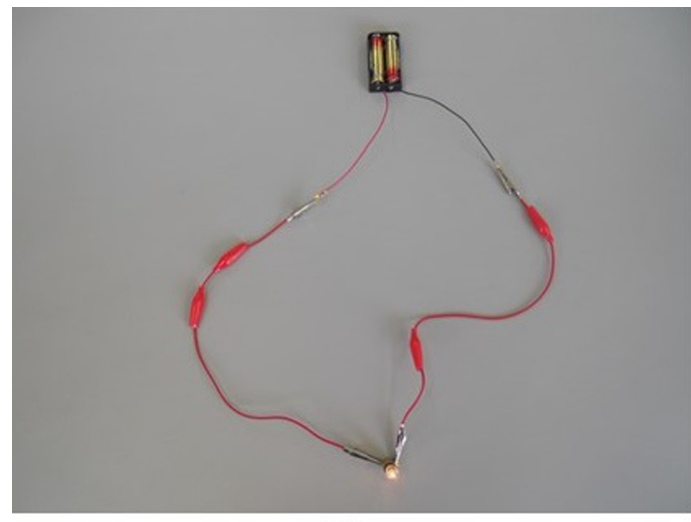

(a) o objetivo de observar um dispositivo que não segue a Lei de Ohm. Os alunos foram então submetidos a uma avaliação, verificando assim o aprendizado dos mesmos.

\section{E2: Abordagem teórica seguida da abordagem experimental virtual}

Na Estratégia 2 (E2), a abordagem teórica feita foi bastante próxima à E1. As aulas experimentais virtuais foram ministradas no laboratório de informática da unidade escolar, com o software do PhET instalado. A turma foi dividida em grupos de 20 indivíduos, e foi solicitado que executassem a simulação computacional em duplas.

Inicialmente, foi feita uma explicação sobre o funcionamento básico do software, com o programa projetado numa tela. As duplas foram então convidadas a montar os circuitos juntamente com o professor, para que aprendessem e se acostumassem com os comandos do software, o que foi um processo rápido. O primeiro circuito montado foi simples, com uma pilha e uma lâmpada, conforme mostra a figura $2(\mathrm{a})$.

Após essa montagem, o professor solicitou aos alunos que ligassem dois amperímetros, um antes e outro depois da lâmpada, para verificar a intensidade da corrente elétrica no circuito, como mostrado na figura 2(b).

Após esse primeiro contato com o software, foi solicitado aos alunos que reiniciassem o programa, e realizassem a atividade experimental proposta, utilizando o resistor.

\section{E3: Abordagem experimental com experimento real}

Na terceira estratégia (E3), o assunto foi apresentado à turma por meio de uma demonstração experimental utilizando equipamentos reais em sala de aula. A primeira aula foi iniciada montando-se um circuito elétrico com pilha e lâmpada com equipamentos reais, três alunos da turma auxiliaram na montagem. A partir daí, explicouse o conceito de corrente elétrica. Foram colocados no circuito dois amperímetros (um antes e outro depois da

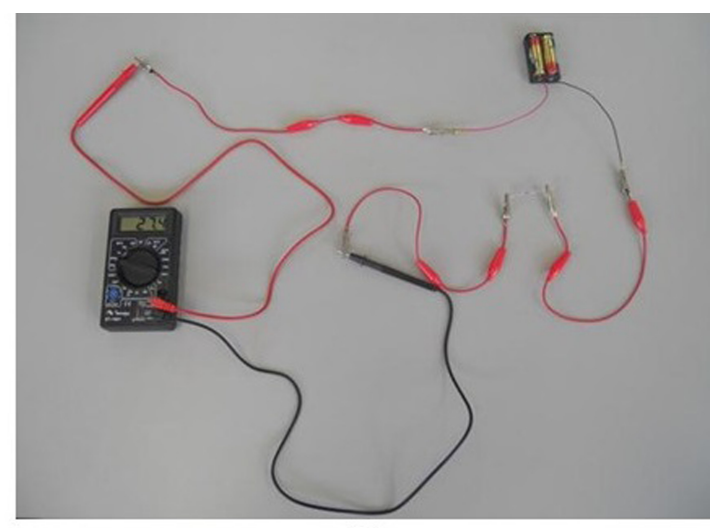

(b)

Figura 1: (a) Circuito simples: pilha e lâmpada e (b) Circuito: pilha, resistor e amperímetro. Fonte: Foto dos autores 


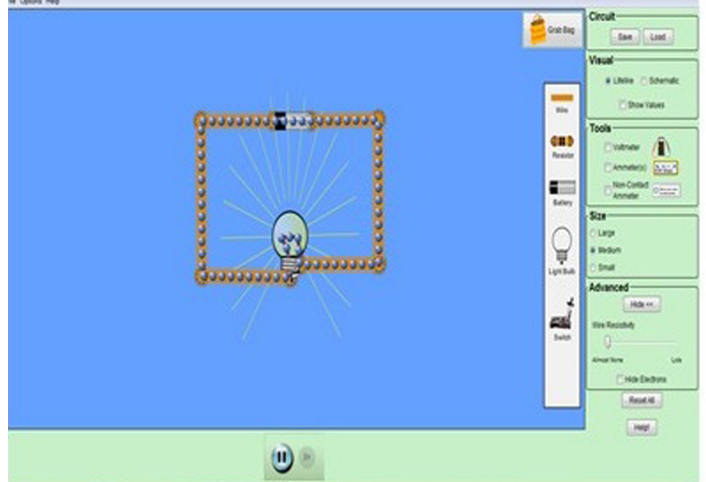

(a)

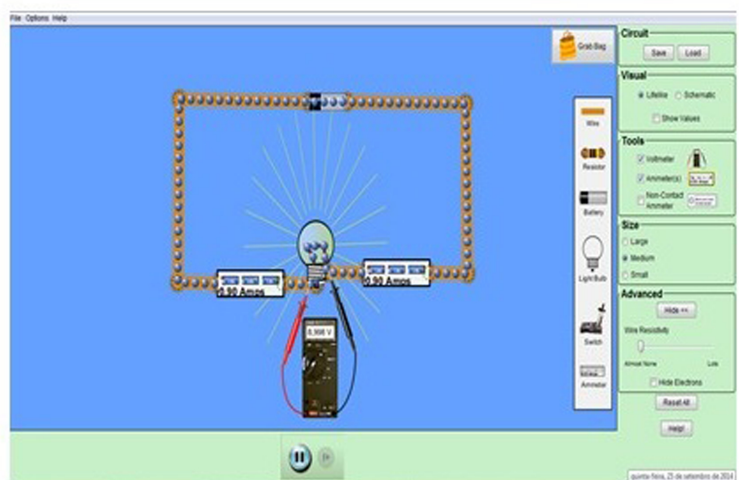

(b)

Figura 2: (a) Modelo de circuito pilha e lâmpada

e (b) circuito pilha e lâmpada com medidores no PhET. Fonte: Universidade do Colorado (2014) [25]

lâmpada) e os alunos puderam ver que a intensidade da corrente tem o mesmo valor nos dois pontos do circuito. Foi então resolvido um exercício no quadro pelo professor e solicitada a resolução de outro exercício pelos alunos.

Na segunda aula foi introduzido o conceito de resistência elétrica e a lei de Ohm, resolvidos exercícios pelo professor e solicitada a resolução de exercícios pelos alunos. As aulas experimentais, uma utilizando resistor e outra utilizando lâmpadas, foram ministradas nos mesmos moldes daquelas ministradas na Estratégia 1. Finalmente foram aplicadas as avaliações.

\section{E4: Abordagem experimental utilizando simulação computacional}

Na quarta estratégia (E4) é apresentada à turma uma abordagem também experimental, nos mesmos moldes da apresentada em E3, mas utilizando-se a simulação computacional. A abordagem iniciou-se com uma demonstração da simulação computacional do PhET, projetada em uma tela. Primeiramente foi montado um circuito elétrico com pilha e lâmpada. Explicou-se, então, o conceito de intensidade de corrente elétrica, e mostrou-se que esta é a mesma no circuito, colocando-se dois amperímetros (um antes e outro depois da lâmpada) para medi-la.

Para a segunda aula, foi introduzido o conceito de resistência elétrica. Novamente, projetou-se um circuito elétrico com pilha, resistor e medidores em uma tela, e fez-se a leitura da medição da intensidade da corrente elétrica e da tensão juntamente com os alunos. Fez-se o mesmo procedimento para duas, três e quatro pilhas, montando-se na lousa uma tabela com esses valores. A partir daí, a lei de Ohm foi explicada mostrando-se que os valores de $\mathrm{V}$ e i eram diretamente proporcionais, e a resistência constante e montou-se na lousa um gráfico $\mathrm{V}$ $\mathrm{x}$ i, obtendo-se uma reta. Foram resolvidos dois exercícios teóricos pelo professor, um sobre corrente elétrica e outro sobre a Lei de Ohm, e foi solicitada a resolução pelos alunos de mais dois exercícios.
Em outra data, foram marcadas as aulas experimentais no laboratório de informática, utilizando-se as simulações do PhET, no mesmo molde anterior (E2).

\subsection{Instrumentos para avaliação}

Inicialmente foi necessário determinar qual o nível de conhecimento prévio dos alunos sobre o assunto. Este ponto é muito importante, pois as turmas do ensino médio desta unidade escolar são bastante heterogêneas, advindos de cursos técnicos modulares como Administração, Edificações, Enfermagem, Informática, Logística, Mecânica, Meio Ambiente, Nutrição e Serviços Jurídicos. Posteriormente, após a participação dos alunos nas atividades das diferentes abordagens, um questionário pós-teste permitiu a identificação de possíveis ganhos conceituais.

As questões que compõem o pré-teste (Apêndice A) foram em sua maioria retiradas de Máximo e Alvarenga ${ }^{3}$ (2011) [26], algumas sofrendo adaptações. O questionário pós-teste, mostrado no Apêndice B, foi elaborado com questões de múltipla escolha retiradas de concursos vestibulares, que priorizam o conceito em detrimento do cálculo.

Os testes que foram aplicados para a verificação da aprendizagem, após as aulas teóricas e/ou atividades experimentais foram os mesmos utilizados anteriormente, entretanto, algumas questões foram modificadas, com alteração de dados numéricos e redação.

$\mathrm{Na}$ aplicação das avaliações foi solicitada a identificação do aluno, para posterior validação, de acordo com os critérios mínimos elencados a seguir: ter feito todas as avaliações, inclusive o pré-teste; ter frequentado no mínimo $50 \%$ das aulas. Além disso, para alunos das turmas que trabalharam com os experimentos reais: ter participado da aula experimental, na qual foi utilizado o resistor; e para alunos das turmas que trabalharam com experi-

\footnotetext{
${ }^{3}$ Essa obra foi aprovada no Programa Nacional do Livro Didático nas edições PNLEM 2007, PNLD 2012 e 2015.
} 
mentos virtuais: ter participado da aula experimental, utilizando o software do PhET.

\section{Pré-teste}

O pré-teste consistiu de oito questões dissertativas sobre as características da corrente elétrica em circuitos ligados em série, resistores ôhmicos e não-ôhmicos e cálculo de tensões. As questões do pré-teste encontram-se no Apêndice A.

As questões podem ser classificadas de acordo com as respectivas competências e habilidades requeridas do aluno em cada uma delas, com base nos PCN+ Ensino Médio [2]. Optou-se por escolher uma competência a ser avaliada para cada questão, mesmo havendo a possibilidade de avaliação de mais competências.

Assim, na primeira questão, ao analisar o sentido da corrente elétrica no circuito dado, o aluno seria capaz de "reconhecer, utilizar, interpretar e propor modelos explicativos para fenômenos ou sistemas naturais ou tecnológicos, reconhecendo suas condições de aplicação"[2]. Na segunda questão, a análise do valor da corrente elétrica permitiria a identificação de fenômenos naturais ou grandezas em um dado domínio do conhecimento científico e o estabelecimento de relações; identificação de regularidades, invariantes e transformações, além do reconhecimento da conservação de determinadas grandezas, como massa, carga elétrica, corrente, etc., utilizando essa noção de conservação na análise de situações dadas [2]. Na terceira questão, os alunos, ao interpretar o papel do motor no circuito dado, seriam instigados a identificar transformações de energia e a conservação que dá sentido a essas transformações, quantificando-as quando necessário; a identificar formas de dissipação de energia e limitações quanto aos tipos de transformações possíveis, impostas pela existência, na natureza, de processos irreversíveis. As questões 4, 5, 6 e 7, envolvendo a interpretação de gráficos e tabelas, requerem a leitura, articulação e interpretação de símbolos e códigos em diferentes linguagens e representações: sentenças, equações, esquemas, diagramas, tabelas, gráficos e representações geométricas [2]. Finalmente, na questão 8, ao solicitar que os alunos montem um experimento com determinadas características e relatem o processo, busca-se desenvolver competências e habilidades relacionadas à elaboração de comunicações orais ou escritas para relatar, analisar e sistematizar eventos, fenômenos, experimentos, questões, entrevistas, visitas, correspondências, bem como a elaboração de relatórios analíticos, apresentando e discutindo dados e resultados, seja de experimentos ou de avaliações críticas de situações, fazendo uso, sempre que necessário, da linguagem física apropriada [2]

A correção do pré-teste foi feita atribuindo para cada um dos 21 itens uma nota na escala de 0 a 10 , onde 0 é totalmente inconsistente e 10 é totalmente consistente com a explicação cientificamente aceita. Desta forma, o aluno poderia totalizar no máximo 210 pontos. Assim, as notas foram normalizadas para uma escala de 0 a 100. Como tratavam-se de questões abertas, é importante especificar como foi realizada a correção dos itens.

No caso de respostas constituídas por um número seguido de sua unidade foram atribuídos oito pontos para alunos que ou erraram a unidade ou não a colocaram. Em alguns casos, a avaliação foi feita levando em consideração partes da resposta dos alunos. Desta maneira, no item a, da questão 5 , foram atribuídos cinco pontos (metade do valor) para quem respondeu que o valor da corrente aumenta, sem especificar que duplicaria. No item a, da questão 6, quem escreveu que o resistor não é ôhmico sem justificar a resposta, não teve pontos atribuídos. Para justificativas do tipo "os valores não seguem um padrão para ser ôhmico", "porque não se mantém constante", "porque há uma variação", "porque ele oscila", "porque não é uma reta", "o gráfico não é uma constante", foram atribuídos cinco pontos, pois estas respostas indicam que o aluno conseguiu entender o conceito, mas não conseguiu se expressar corretamente. No caso do item b, da questão 7, respostas como "até certo ponto, depois não é mais", "ele não é constante", "ele não segue uma reta" (neste último não acompanhado do esboço do gráfico), foram consideradas parcialmente corretas, sendo atribuídos cinco pontos.

\section{Pós-teste}

O pós-teste consistiu de nove questões do tipo múltipla escolha que foram agrupadas de acordo com as competências e habilidades que constam na matriz de competências do Exame Nacional do Ensino Médio (ENEM). As questões do pós-teste são mostradas no Apêndice B.

Desta maneira, as questões 1, 3, 6, 7, 8 e 9 envolvem a leitura de tabelas ou gráficos, e são caracterizadas como "H 17 - Relacionar informações apresentadas em diferentes formas de linguagem e representação, usadas nas ciências físicas, químicas ou biológicas, como texto discursivo, gráficos, tabelas, relações matemáticas ou linguagem simbólica". Na questão 4, a análise da leitura da corrente em um circuito simples, requer a habilidade "H 20 - Caracterizar causas ou efeitos dos movimentos de partículas, substâncias, objetos ou corpos celestes" Nas questões 2 e 5, espera-se que o aluno ao caracterizar um condutor ôhmico seja capaz de "H 21 - Utilizar leis físicas e (ou) químicas para interpretar processos naturais ou tecnológicos inseridos no contexto da termodinâmica e (ou) do eletromagnetismo".

\section{Resultados obtidos}

Após a aplicação de todas as atividades (pré-testes, aulas e pós-testes), iniciou-se a análise dos dados coletados das avaliações aplicadas aos alunos. Nesta seção apresentamse os resultados obtidos. 


\subsection{Caracterização inicial das turmas e distribuição das abordagens}

O pré-teste teve por objetivo verificar os conhecimentos prévios dos alunos, além de contribuir para caracterizar as turmas com base no seu aproveitamento. O quadro 1 mostra o número de alunos avaliados e o aproveitamento médic 4 das turmas no pré-teste

Pode-se verificar que a turma do $3^{\circ} \mathrm{A}$ tem um perfil um pouco diferente das demais, apresentando a maior média. As demais turmas têm um perfil semelhante, com pouca variação. Desta forma, fez-se a distribuição das estratégias conforme indicado no quadro 1. As estratégias E3 (abordagem experimental com experimento real) e E4 (abordagem experimental com experimento virtual) foram aplicadas nas turmas do $3^{\circ} \mathrm{D}$ e do $3^{\circ} \mathrm{C}$, respectivamente, uma vez que as mesmas apresentam perfil semelhante, permitindo uma comparação das duas estratégias no que diz respeito ao aprendizado dos alunos. As estratégias E1 (abordagem teórica seguida da abordagem experimental real) e E2 (abordagem teórica seguida da abordagem experimental com simulação computacional) foram aplicadas nas turmas do $3^{\circ} \mathrm{A}$ e do $3^{\circ} \mathrm{B}$, respectivamente. Assim, foi possível verificar qual o impacto das abordagens experimentais, após uma abordagem teórica em duas turmas de perfis diferentes.

\subsection{Análise dos conhecimentos prévios dos alunos}

Com base no resultado dos pré-testes aplicados pode-se observar que os alunos têm pouquíssimo conhecimento prévio sobre o assunto, uma vez que a maioria destes ficou com nota abaixo de 20, em uma escala de 0 a 100 , como pode ser visto pela média das turmas (Quadro 1). Importante destacar que muitos alunos não apresentaram nenhum conhecimento sobre o assunto - notas zero foram atribuídas a sete ( $21 \%$ do total), oito ( $34 \%$ do total), 12 ( $50 \%$ do total) e sete alunos $(26 \%$ do total) das turmas do $3^{\circ} \mathrm{A}, 3^{\circ} \mathrm{B}, 3^{\circ} \mathrm{C}$ e $3^{\circ} \mathrm{D}$, respectivamente. Menos de $20 \%$ dos alunos obtiveram notas entre 20 e 40 , e uma porcentagem menor ainda na faixa de 40 a 60 . Nenhum aluno pontuou nas faixas de 60 a 80 , ou de 80 a 100 . O rendimento das turmas foi muito similar, com a turma do $3^{\circ} \mathrm{A}$ apresentando um resultado um pouco melhor.

Uma possível explicação para esta discrepância nos resultados entre as turmas, é o fato de os alunos da turma do $3^{\circ} \mathrm{A}$ serem mais dedicados e preocupados com o estudo, o que pode ter motivado a tentar responder com mais atenção às questões do pré-teste, mesmo não tendo ainda conhecimento formal sobre o assunto. A turma do $3^{\circ} \mathrm{D}$ tem mais alunos cursando o ensino técnico, que já têm um conhecimento prévio do assunto, o que também pode ter contribuído para um menor número de notas zero no pré-teste, quando comparados com os alunos do $3^{\circ} \mathrm{B}$ e $3^{\circ} \mathrm{C}$.

\footnotetext{
${ }^{4}$ Foi feita uma média simples das notas de cada turma.
}

\subsection{Aproveitamento dos alunos}

Esta seção apresenta o aproveitamento dos alunos obtido por meio das avaliações aplicadas. Para efeito de comparação dos métodos de ensino, o aproveitamento é separado por abordagem. O número de alunos envolvidos foi de $34,29,24$ e 27 respectivamente nas turmas do $3^{\circ} \mathrm{A}$, $3^{\circ} \mathrm{B}, 3^{\circ} \mathrm{C} \mathrm{e} 3^{\circ} \mathrm{D}$ de acordo com o critério de validação definido anteriormente.

\section{Após a aula teórica tradicional}

Após a aula teórica pode-se observar uma melhora nas notas dos alunos, diminuindo significativamente o número de alunos com notas abaixo de 20. Somente os alunos do $3^{\circ} \mathrm{A}$ e $3^{\circ} \mathrm{B}$ trabalharam com a abordagem estritamente teórica em sala de aula e fizeram uma avaliação logo após a mesma. Os resultados dessa avaliação podem ser vistos no gráfico 1 (a) e na tabela 1.

\section{Após as aulas experimentais}

Quando se analisam as médias, pode-se observar que todas as turmas atingem notas acima de 50 pontos (em um total de 100 pontos), conforme mostra a tabela 1 . Pode-se verificar que nas turmas em que ocorreram as aulas com abordagem teórica houve efeito no aprendizado após as aulas expositivas (como era esperado) e outra melhora após as aulas experimentais (tanto reais quanto virtuais). No caso do $3^{\circ} \mathrm{A}$, as notas médias foram 17 para o pré-teste, 46 para a avaliação após aula teórica e 65 para a avaliação após aula experimental. No caso do $3^{\circ} \mathrm{B}$, os valores ficaram em 11, 44 e 52, respectivamente. Esse resultado poderia ser atribuído ao fato de que o conteúdo foi novamente visto pelos alunos na abordagem experimental, e que esta repetição por si só reforçaria o aprendizado.

Entretanto, verifica-se que o aproveitamento dos alunos das turmas que começaram com as abordagens experimentais $\left(3^{\circ} \mathrm{C}\right.$ e $\left.3^{\circ} \mathrm{D}\right)$ - e portanto, não tiveram essa repetição - é sempre, em média, maior do que o aproveitamento dos alunos que foram avaliados logo após a abordagem estritamente teórica $\left(3^{\circ} \mathrm{A}\right.$ e $\left.3^{\circ} \mathrm{B}\right)$. Este fato é um forte argumento de que a abordagem experimental é um fator que contribui para o aprendizado dos alunos, antecedida ou não de uma abordagem teórica. Os resultados da avaliação após a abordagem experimental podem ser vistos no gráfico 2 (b).

\subsubsection{Comparação do aproveitamento das turmas com diferentes abordagens}

Quando se analisam os resultados de cada turma, pode-se verificar que sempre houve um incremento na aprendizagem após a abordagem experimental. Os gráficos 2(a) e 2(b) mostram esse fato. Nos gráficos, o pré-teste, a avaliação após aula teórica e a avaliação após atividade experimental estão denominadas, respectivamente, por PRÉ, PÓS-T E PÓS-E. 
Quadro 1: Distribuição das estratégias por turma

\begin{tabular}{lccl}
\hline Turma & $\mathrm{N}^{\circ}$ de alunos & Média & Estratégias \\
\hline $3^{\circ} \mathrm{A}$ & 40 & 17 & E1 - Abordagem teórica (tradicional) seguida do experimento real. \\
$3^{\circ} \mathrm{B}$ & 39 & 11 & $\mathrm{E} 2$ - Abordagem teórica (tradicional) seguida do experimento virtual \\
$3^{\circ} \mathrm{C}$ & 38 & 12 & $\mathrm{E} 4$ - Abordagem experimental virtual \\
$3^{\circ} \mathrm{D}$ & 36 & 13 & E3 - Abordagem experimental com equipamentos reais. \\
\hline \multicolumn{2}{l}{ Fonte: }
\end{tabular}

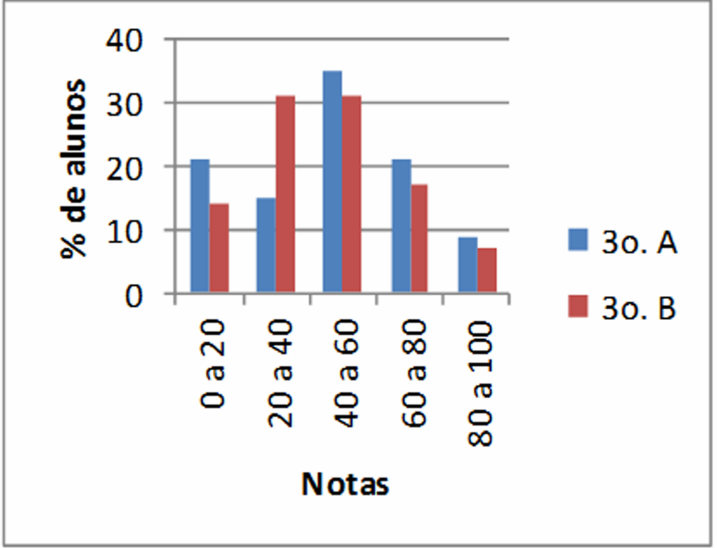

(a)

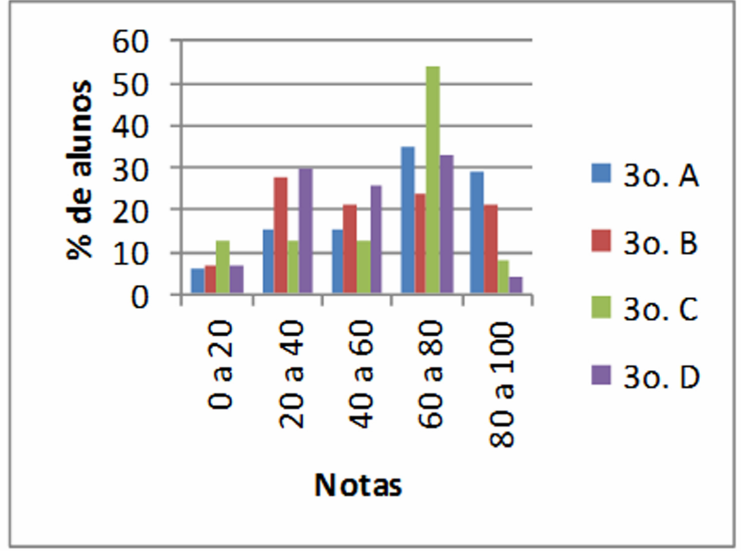

(b)

Gráfico 1: Porcentagem de alunos por nota após aulas (a) teóricas (b) experimentais. Fonte: Dados da pesquisa

Outra análise merece ser feita. Verifica-se que no caso das estratégias 1 e 2 , os alunos do $3^{\circ} \mathrm{A}$, que trabalharam com a abordagem experimental real obtiveram nota média maior, quando comparados aos alunos do $3^{\circ} \mathrm{B}$, que trabalharam a abordagem experimental computacional. No caso das estratégias 3 e 4 verifica-se que os alunos do $3^{\circ} \mathrm{C}$, que trabalharam com a abordagem experimental utilizando simulação computacional obtiveram nota média maior, quando comparados aos alunos do $3^{\circ} \mathrm{D}$, que trabalharam a abordagem experimental real. Acrescentese que os alunos da turma do $3^{\circ} \mathrm{C}$ partiram com nota média menor no pré-teste e chegaram a uma nota média maior no pós-teste. Para uma possível explicação desses fatos deve-se lembrar que os testes estão sendo feitos

Tabela 1: Resultados dos pós-testes por turma

\begin{tabular}{lccc}
\hline Turma & No. de Alunos & Média pós-aula expositiva & Média final \\
\hline $3^{\circ}$. A & 34 & 46 & 65 \\
$3^{\circ}$. B & 29 & 44 & 52 \\
$3^{\circ}$ C & 24 & - & 58 \\
$3^{\circ}$. D & 27 & - & 50 \\
\hline
\end{tabular}

Fonte: Dados da pesquisa

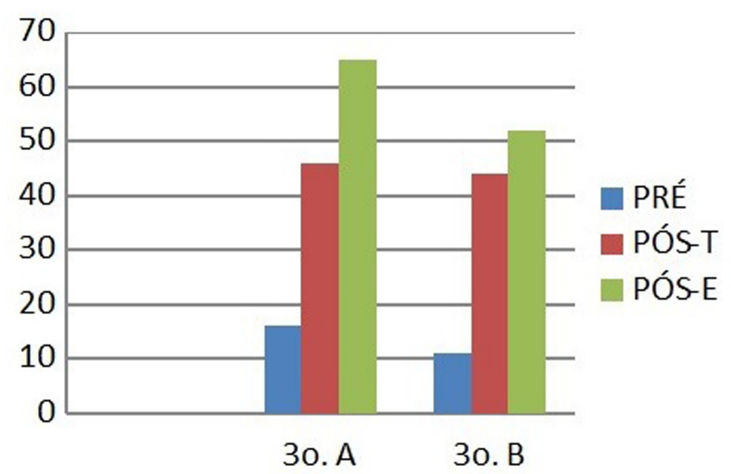

(a)

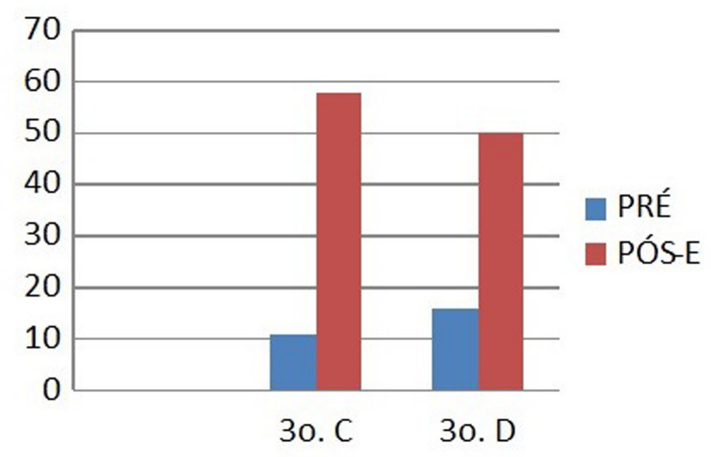

(b)

Gráfico 2: Evolução dos alunos do (a) $3^{\circ} \mathrm{A}$ e $3^{\circ} \mathrm{B}$ e (b) $3^{\circ} \mathrm{C}$ e $3^{\circ} \mathrm{D}$. Fonte: Dados da pesquisa 
com pessoas, e que seus resultados dependem também de outros fatores como atenção às aulas, interesse dos alunos e até mesmo condição dos mesmos na data de aplicação dessas avaliações. É interessante chamar a atenção para o fato de que esta é a situação real de uma sala de aula.

Foi observado também que um maior número de alunos das turmas que passaram pela abordagem com simulação computacional $\left(3^{\circ}\right.$. B e $3^{\circ}$. C) respondeu corretamente à questão 4 do pós-teste, que apresenta um circuito simples, com bateria, lâmpada e amperímetro. Uma possível explicação para esse fato é que, na abordagem com simulação computacional a visualização das ligações é mais clara, facilitando a análise do circuito. $\mathrm{Na}$ abordagem real essa visualização fica prejudicada pelo emaranhado de fios, o que pode ter influenciado nas respostas incorretas dos alunos.

Nas questões 2 e 8 do pós-teste houve um índice de acerto muito baixo, o que pode ser explicado pela falta de atenção dos alunos. Na questão 8, ao analisar o gráfico, os alunos podem não ter observado que se tratava de um gráfico $\mathrm{R}$ x i e não de um gráfico $\mathrm{V}$ x i. Na questão 2, podem não ter observado que a pergunta versava sobre a variação da resistência e não sobre a variação da corrente.

A questão 5 do pós-teste também apresentou um índice de acerto baixo, visto que os alunos têm certa dificuldade em lembrar conceitos de proporcionalidade direta de maneira correta. Muitos alunos marcaram a alternativa c, que considera a resistência proporcional à tensão aplicada. Os resultados indicam um condicionamento dos alunos a reconhecer uma relação de proporcionalidade para um resistor ôhmico, mas também indicam que estes não perceberam que a resistência fica constante neste caso.

As demais questões apresentam índice de acerto satisfatório e as discrepâncias entre as turmas podem ser consideradas desprezíveis.

\subsection{Uma proposta de abordagem considerada eficiente}

Com base nos trabalhos feitos com os alunos, verificou-se a possibilidade de uma quinta abordagem, que poderia ser mais eficiente no aprendizado dos conceitos relacionados a circuitos elétricos e Lei de Ohm. A ideia principal é misturar elementos de simulações computacionais e atividades experimentais reais. O planejamento das aulas utilizando-se esta abordagem é sugerido no quadro 2.

Inicialmente propõe-se utilizar o simulador do $P h E T$ para apresentar aos alunos os conceitos de corrente elétrica, resistência elétrica e Lei de Ohm. O simulador contribuiria para uma aprendizagem eficiente, ao tornar possível a manipulação de experimentos simples, permitindo a visualização clara das ligações, evitando um primeiro contato com o emaranhado de cabos de ligação, o que poderia desmotivar o aluno. De fato, Duarte (2012, p. 528) [27], comenta que “[...] há situações, quando o professor apresenta conceitos e fenômenos com os quais os estudantes não estão familiarizados, em que experi- mentos simples, mesmo demonstrativos, podem ser muito enriquecedores".

Depois dessa etapa, os alunos estariam preparados para fazer a atividade experimental real com o resistor, e se houver tempo disponível, com a lâmpada. As atividades experimentais nas quais o aluno participa ativamente, manuseando dispositivos e equipamentos, executando o experimento e coletando dados são bastante proveitosas. Verifica-se que a grande maioria dos alunos gosta de participar dessas atividades, despertando assim, o seu interesse pela Física.

Esta opção está em acordo com os resultados obtidos em Finkelstein et al (2005) [13].

É claro que esta opção de abordagem será viável para professores que têm à sua disposição estrutura para desenvolvê-la. Também é importante destacar que o professor deverá primeiramente avaliar a situação da sala de aula, para planejar as aulas e adaptar a abordagem para a sua realidade. Entre os pontos que devem ser considerados, destacam-se: o perfil de cada turma; o número de aulas disponível; a possibilidade de se aplicar as atividades experimentais fora do horário normal de aulas.

Desta forma, pode-se utilizar as vantagens de cada abordagem para facilitar o aprendizado dos alunos.

\section{Considerações finais}

Este trabalho reforça a importância das atividades experimentais no ensino de Física, principalmente quando comparadas com aulas expositivas, bem como algumas possibilidades de se propor essas atividades aos alunos. O objetivo da pesquisa realizada foi determinar se atividades experimentais (reais ou baseadas em simulações computacionais) permitem maior eficiência no aprendizado dos alunos. Com a resposta afirmativa a esta questão, foi investigado qual das formas de atividades experimentais produziriam melhor efeito.

Pode-se verificar que as abordagens, tanto real quanto virtual, foram proveitosas para os alunos - tanto na assimilação do conteúdo (verificada por meio das avaliações) quanto no seu interesse e motivação, verificados por meio das opiniões dos próprios alunos. Estes resultados são coerentes com os resultados obtidos em trabalhos como o de Alves (2006) [4], que fez um estudo do impacto de atividades experimentais reais na aprendizagem dos alunos, e em trabalhos que compararam o uso de atividades experimentais reais e virtuais [14-18].

Durante a aplicação das estratégias, foram verificadas algumas vantagens e desvantagens, destacadas pelos próprios alunos, de uma abordagem em relação à outra. Uma grande vantagem da abordagem experimental com equipamentos reais é que o aluno entra em contato com a realidade, fazendo medidas e obtendo resultados não tão exatos quanto àqueles que aparecem nos exercícios propostos dos livros didáticos. A sua desvantagem está na dificuldade de execução, dada a confusão de ligações com 
os aparelhos de medidas e fios de conexão. Esta confusão com os cabos de ligação, que pode ser minimizada com orientações do professor, também é relatada no trabalho de Finkelstein et al (2005) [13].

No caso da abordagem experimental com simulações computacionais, suas vantagens são a simplicidade, a facilidade de utilização e entendimento do programa. Uma desvantagem está no fato de que em alguns casos, o simulador não representa a realidade de fato. Um exemplo disto é que, no simulador utilizado, a lâmpada segue a Lei de Ohm, quando, na realidade, ela não deveria seguir. Foi por este motivo que optou-se em propor aos alunos somente a atividade experimental com o resistor nesta abordagem. De fato, Medeiros e Medeiros (2002, p. 4) [11] comentam que "um sistema real é frequentemente muito complexo e a maioria das simulações que o descrevem é geralmente baseada em modelos que representam simplificações e aproximações da realidade". O professor deve estar atento a este fato durante o planejamento de suas aulas, a fim de não reforçar uma informação que não corresponde à realidade.

Verificou-se que, no assunto circuitos elétricos e Lei de Ohm, uma combinação das duas abordagens poderia ser mais eficiente - a abordagem virtual permite ao aluno verificar alguns aspectos microscópicos comentados pelo professor (e não visualizados no mundo real) e a abordagem real permite o contato do aluno com o cotidiano, verificando como as coisas acontecem, manipulando dispositivos e equipamentos. Esta combinação de abordagens mostrou-se mais eficiente nos trabalhos relatados por Zacharia e Anderson (2003) [18], Zacharia, Olympiou e Papaevripidou (2008) [15] e Zacharia (2007) [19], em que atividades reais e virtuais foram aplicadas em alunos da graduação ou professores de física. Para alunos da educação básica, os resultados dos trabalhos de Jaakkola e Nurmi (2008) [20], Ronen e Eliahu (2000) [21] e Moro, Neide e Rehfeldt (2016) [22], também indicam que a combinação de atividades reais e virtuais melhora a compreensão sobre tópicos da Física.

Esta abordagem, considerada ideal, pode ser trabalhada no estudo de outros assuntos dentro do Eletromagnetismo, pois permite melhor visualização do mundo microscópico, fazendo com que o aluno compreenda mais facilmente os modelos para explicação do mundo que o rodeia. Outros ramos da Física, em especial a Termodinâmica, que trabalha com modelos microscópicos, podem se valer dessa abordagem para facilitar a compreensão dos conceitos físicos. Outras disciplinas que utilizam modelos microscópicos também poderiam fazer uso desta estratégia, como por exemplo a Química. Por sinal, esta foi a fala espontânea de alguns alunos durante a aplicação das atividades experimentais, ao destacarem que outras disciplinas poderiam ter atividades de laboratório.

Planejar e executar uma aula experimental não é uma tarefa simples. Exige empenho e conhecimento do professor, maior tempo para preparação das aulas e material disponível. Embora a maioria das escolas não tenha estrutura para atividades experimentais, o professor pode criar condições para que aconteçam. A maneira mais simples de introduzir atividades experimentais em sala de aula, pode ser através da demonstração. Há experimentos simples em todas as áreas da Física, muitos deles com caráter lúdico, que podem transformar o ambiente de sala de aula, despertando o interesse dos alunos e motivando-os a aprender por meio de discussões a respeito do fenômeno apresentado.

Além disso, há a possibilidade de o professor utilizar recursos computacionais para trabalhar com experimentos, o que pode impactar na aprendizagem dos estudantes. Uma vez que a atual geração tem grande familiaridade com o uso de tecnologias, esse também é um fator que contribui para aguçar a sua curiosidade e vontade de

Quadro 2: Abordagem com simulação computacional seguida do experimento real

\begin{tabular}{|c|c|c|}
\hline Aula & Tempo previsto & Assunto e/ou Atividade \\
\hline 1 & $50 \mathrm{~min}$ & $\begin{array}{l}\text { Corrente elétrica (projetar a tela do PhET e montar um circuito elétrico simples (pilhas + } \\
\text { lâmpada), mostrando o sentido do movimento dos elétrons. Colocar um amperímetro de cada } \\
\text { lado da lâmpada e mostrar aos alunos que a corrente que passa pelo circuito não se modifica). } \\
\text { Resolver um exercício em sala de aula. }\end{array}$ \\
\hline & $25 \min$ & Corrente elétrica - propor exercício para que os alunos resolvam em sala. \\
\hline 2 & $25 \mathrm{~min}$ & Resistência elétrica. Discussão do conteúdo. \\
\hline 3 & $50 \mathrm{~min}$ & $\begin{array}{l}\text { Lei de Ohm (projetar a tela do } P h E T \text { ) e montar um circuito elétrico simples (pilha + resistor), } \\
\text { colocando o amperímetro e o voltímetro e fazendo as medições de corrente elétrica (i) e tensão } \\
\text { (V). Repita o procedimento para } 2,3 \text { e } 4 \text { pilhas. Mostrar aos alunos os resultados, comentando } \\
\text { sobre a proporcionalidade direta entre } \mathrm{V} \text { e i, o valor constante da resistência R e o fato do } \\
\text { gráfico V x i ser uma reta inclinada. }\end{array}$ \\
\hline & $25 \mathrm{~min}$ & Lei de Ohm - resolver um exercício em sala de aula. \\
\hline 4 & $25 \mathrm{~min}$ & Lei de Ohm - propor exercício para que os alunos resolvam em sala. \\
\hline $5 / 6$ & $100 \mathrm{~min}$ & $\begin{array}{l}\text { Aplicar a atividade experimental - explicação, execução do experimento em laboratório e coleta } \\
\text { dos dados. }\end{array}$ \\
\hline $7 / 8$ & $100 \min$ & Elaboração do relatório. \\
\hline 9 & $50 \mathrm{~min}$ & $\begin{array}{l}\text { Aplicar a atividade experimental (utilizando a lâmpada) - explicação, execução do experimento } \\
\text { em laboratório, coleta dos dados. }\end{array}$ \\
\hline 10 & $50 \mathrm{~min}$ & Elaboração do relatório. \\
\hline TOTAL & 10 aulas & \\
\hline
\end{tabular}


aprender. Não é raro durante a aplicação da atividade virtual os alunos perguntarem se há uma cópia disponível do programa para utilizarem em seus computadores, o que mostra o seu interesse.

\section{Material Suplementar}

O seguinte material suplementar está disponível online: Apêndice A

Apêndice B

\section{Referências}

[1] D. Fiorentini e S. Lorenzato, Investigação em educação matemática (Autores Associados, Campinas, 2012), $3^{\mathrm{a}} \mathrm{ed.}$

[2] BRASIL. PCN+ Ensino Médio: Orientações Educacionais complementares aos Parâmetros Curriculares Nacionais, disponível em http://portal.mec.gov.br/seb/ arquivos/pdf/CienciasNatureza.pdf

[3] C. Fiolhais e J. Trindade, Rev. Bras. Ens. Fís. 25, 3 (2003).

[4] V.F. Alves, A inserção de atividades experimentais no ensino de física em nível médio: em busca de melhores resultados de aprendizagem. Dissertação de Mestrado, Universidade de Brasília, Brasília (2006).

[5] E.F. Sá, Os propósitos de atividades experimentais na visão de alunos e professores. Dissertação de Mestrado, Universidade Federal de Minas Gerais, Belo Horizonte (2003).

[6] T.D. Ribeiro, A.M. Almeida e P.S. Carvalho, Rev. Bras. Ens. Fís. 34, 4 (2012).

[7] M.G. Sérè, S.M. Coelho e A.D. Nunes, Cad. Bras. Ens. Fís. 20, 1 (2003).

[8] I.C.C. Monteiro, M.A.A. Monteiro, J.S.E. Germano e A. Gaspar, Cad. Bras. Ens. Fís. 27, 2 (2010).

[9] A.H.H. Cenne, Tecnologias computacionais como recurso complementar no ensino de física térmica. Dissertação de Mestrado, Universidade Federal do Rio Grande do Sul, Porto Alegre (2007).

[10] P.R.S. Rosa, Rev. Bras. Ens. Fís. 17, 2 (1995).

[11] A. Medeiros, C.F.D. Medeiros, Rev. Bras. Ens. Fís. 24, 2 (2002).

[12] J.A. Macêdo A.G. Dickman e I.S.F. Andrade, Cad. Bras. Ens. Fís. 29, 1 (2012).

[13] N.D. Finkelstein, W.K. Adams, C.J. Keller, P.B. Kohl, K.K. Perkins, N.S. Podolefsky, S. Reid e R. LeMaster, Phys. Rev. ST Phys. Educ. Res. 1, 010103 (2005).

[14] Z.C. Zacharia e C.P. Constantinou, Am. J. Phys, 76 4/5 (2008).

[15] Z.C. Zacharia, G. Olympiou e M. Papaevripidou, Journal of Research in Science Teaching 45, 9 (2008).

[16] P.F.T.D. Dorneles, I.S. Araujo e E.A. Veit, Ciência \& Educação 18, 1 (2012).

[17] P.F.T. Dorneles, Integração entre atividades computacionais e experimentais como recurso instrucional no ensino de eletromagnetismo em física geral. Tese de Doutorado, Universidade Federal do Rio Grande do Sul, Porto Alegre (2010).

[18] Z.C. Zacharia e O.R. Anderson, Am. J. Phys 71, 6 (2003).
[19] Z.C. Zacharia, Journal of Computer Assisted Learning 23, 2 (2007).

[20] T. Jaakkola e S. Nurmi, Journal of Computer Assisted Learning 24, 4 (2008).

[21] M. Ronen e M. Eliahu, Journal of Computer Assisted Learning 16, 1 (2000).

[22] F.T. Moro, I.G. Neide e M.J.H. Rehfeldt, Cad. Bras. Ens. Fís. 33, 3 (2016).

[23] D.L. Scarpa e M. Marandino, in Anais do II Encontro Nacional de Pesquisa e Ensino de Ciências, Valinhos, 1999, editado por M.A. Moreira e F. Ostermann (ABRAPEC, Florianópolis, 1999).

[24] J.C. Santos, Experimentos reais e simulações computacionais: Proposta para Ensino de Eletricidade no Nivel Médio. Dissertação de Mestrado, Pontifícia Universidade Católica de Minas Gerais, Belo Horizonte (2015).

[25] https://phet.colorado.edu/en/simulation/ circuit-construction-kit-dc-virtual-lab, acesso em $20 / 11 / 2014$.

[26] A. Máximo e B. Alvarenga, Curso de Física (Scipione, São Paulo, 2011), p. 111, v. 3.

[27] S.E. Duarte, Cad. Bras. Ens. Fís. 29, 1, (2012). 